Mirai. Estudios Japoneses

ISSN-e: 1988-2378

http://dx.doi.org/10.5209/MIRA.57105

\title{
Cosas de Japón de Basil H. Chamberlain: ¿la primera guía cultural sobre Japón?
}

\author{
Dr. José Pazó Espinosa ${ }^{1}$
}

Resumen: Basil H. Chamberlain publicó en 1890 Things Japanese, un extenso libro con formato enciclopédico en el que recogía y describía rasgos culturales de Japón. El libro tuvo un gran éxito, y fue traducido por Gonzalo Jiménez de la Espada al español en la segunda década del siglo XX, si bien dicha traducción nunca vio la luz y se conservó solo parcialmente, hasta su recuperación en el año 2014. En este trabajo, analizamos "Cosas de Japón" como una primera guía cultural dirigida al turista culto de finales del siglo XIX y comienzos del XX. De forma particular, nos centramos en su título y en el concepto que articula el libro como una metáfora cognitiva sobre una cultura diferente, la japonesa: la idea de que Japón es un mundo topsy turvy, un mundo al revés. Indagamos en los orígenes de esa idea, existente ya en los tratados de Alessandro Valignano y, especialmente, de Luis Frois.

Palabras claves: Chamberlain, Jiménez de la Espada; turismo; guía cultural; Meiji.

\section{[en] Things Japanese by Basil H. Chamberlain: the first cultural guide to Japan?}

\begin{abstract}
In 1890, Basil H. Chamberlain published "Things Japanese", an encyclopaedic book on Japan and its culture. The book enjoyed a formidable success and it was translated into Spanish during the second decade of the 20th century by Gonzalo Jiménez de la Espada, although that translation was never published and only survived partially, until its recovery in 2014. Here we analyse Cosas de Japón as one of the first cultural guides for the cultivated tourist of the late 19th and early 20th centuries. In particular, we focus on its title, and the central concept that articulates the book and serves as a cognitive metaphor about a different culture: the idea that Japan is a topsy turvy world, a world upside down. We investigate the origins of this idea, already present in works by Alessandro Valignano and, especially, Luis Frois.
\end{abstract}

Keywords: Chamberlain; Jiménez de la Espada; turism; cultural guide; Meiji.

Sumario. 1. Chamberlain y el turismo en Japón. 2. Cosas de España. 3. El mundo al revés y sus raíces. 4. Conclusiones.

Cómo citar: Pazó Espinosa, J. (2017). Cosas de Japón de Basil H. Chamberlain: ¿la primera guía cultural sobre Japón? (2017), en Mirai. Estudios Japoneses 1, 2017, 113-121.

\section{Chamberlain y el turismo en Japón}

En el año 1890, Basil H. Chamberlain publicó en Japón la primera edición de Things Japanese, libro que tuvo un enorme éxito mantenido a lo largo de gran parte del siglo XX. En la introducción al libro, Chamberlain explica que la razón para escribirlo fue dar respuestas a las numerosas preguntas que los visitantes le hacían sobre Japón:

\footnotetext{
1 Universidad Autónoma de Madrid. jose.pazo@uam.es
} 
Constantemente se nos dirigen preguntas acerca del Japón: ahí van las respuestas, ordenadas en forma de diccionario, no de palabras sino de cosas (¿o, diríamos mejor, en forma de guía, no tanto de lugares como de asuntos?); no una enciclopedia, entiéndase, no el intento, vano para un solo hombre, de tratar hasta agotarlas todas las materias, sino tan solo bosquejos de diversas cosas ${ }^{2}$.

Es decir, su intención fue establecer una guía sobre aspectos culturales y sociales que sirviera de referencia a los numerosos visitantes. Un año antes, en 1889, Chamberlain había publicado, junto W.B. Mason una auténtica guía turística, Handbook for Travellers in Japan ${ }^{3}$. En ella, además de una introducción cultural de casi 100 páginas que parece un resumen de algunas de las entradas de Things Japanese, divide Japón en ocho zonas para orientar al viajero anglohablante: el Japón del este, el Japón central, el Japón del oeste y el mar interior, Shikoku, Kiushu, el Japón del Norte, la isla de Yezo, y Luchu y Formosa. Aunque ya existían otras guías sobre Japón, Chamberlain, con estas dos obras, entra de lleno en lo que podríamos llamar la literatura turística sobre Japón escrita por extranjeros en el propio país. Y de los dos libros, el más importante desde el punto de vista del contenido cultural es seguramente Things Japanese, una pequeña enciclopedia de la época sobre la cultura japonesa. Sin embargo, esta asociación entre cultura y turismo ha estado vigente desde el comienzo de los viajes.

En un sentido moderno, el turismo nació en el siglo XVII asociado al Grand Tour, el viaje que los jóvenes ingleses comenzaron a hacer por las cortes y las ciudades francesas e italianas sobre todo, como forma de aumentar su formación y experiencia. Antes del gran Tour existían sin embargo rutas y peregrinaciones, tanto en Europa como en Japón, asociadas al concepto de lugar sagrado. En el caso del país nipón, estas rutas eran conocidas como Gokaidō, las cinco rutas desde Edo. Constituían el eje del turismo interno, y tenían sus guías meisho de lugares famosos especialmente atractivos. Cuando el emperador Meiji abre las fronteras del país de nuevo, el país se vio invadido por viajeros que no hablaban la lengua japonesa pero que, sin embargo, querían visitar los confines de las islas. Surge así la necesidad de la existencia de guías que les permitan tanto moverse con cierta eficiencia como comprender lo que ven. En este sentido, Chamberlain se establece como una referencia para el viajero y para el curioso sobre Japón.

Hay que tener en cuenta que por esos años, asociada a la compañía de Thomas Cook, aparece la idea del globetrotter ${ }^{4}$, el viajero que da la vuelta al mundo. Chamberlain, en Things Japanese, se ríe de esta figura en una entrada con el mismo nombre, pero de forma paradójica el globetrotter es el cliente principal de sus libros: el viajero de larga distancia que quiere descubrir otros mundos y ver cosas raras y excepcionales. Es en esta época, los finales del siglo XIX, cuando se populariza y glo-

2 Las citas del trabajo de Chamberlain Things Japanese se refieren siempre a la traducción española: CHAMBERLAIN, Basil Hall / PAzó Espinosa, José (trad.) (2014): Cosas de Japón. Gijón: Satori Ediciones, p. 27.

3 Chamberlain, Basil Hall \& Mason, William Benjamin (1989): Handbook for Travellers in Japan. London: John Murray. La sexta edición es accesible en https://archive.org/stream/handbookfortrav00cham\#page/n7/ mode/2up [Consulta: 4/08/2016]

4 Sobre la figura del globetrotter y su relación con Japón, véase el interesante ensayo: HocKLEY, Allen (2010): Globetrotters' Japan: Places. Foreigners on the Tourist Circuit in Meiji Japan. Cambridge: MIT Visualizing Cultures. Véase: https://ocw.mit.edu/ans7870/21f/21f.027/gt_japan_places/ga2_essay.pdf [Consulta: $4 / 08 / 2016]$ 
baliza el concepto moderno de turista, que une viaje con cultura en todas sus formas, culta y popular. Este viajero busca siempre busca "el otro", o mejor dicho, "lo otro", y las sensaciones asociadas a su descubrimiento. Es un viajero que busca salir de sí mismo para reconocerse en algo diferente. Y casi siempre quiere perpetuar esa sensación en forma de memorabilia, que va desde el objeto exótico a la fotografía. En este sentido, todo viajero busca llevarse algo del contexto en el que una vez estuvo.

John Frow, en su artículo Tourism: the Semiotics of Nostalgia (1991) ${ }^{5}$, afirma que el viajero ve lo que le ha sido mostrado en modelo. Esta idea presupone que el viajero, de forma inconsciente ve lo que le han enseñado a ver. O dicho de otra forma, el viajero busca lo que le enseñan a buscar. Y no nos referimos a objetos o lugares (que también lo hace), sino ideas abstractas sobre el lugar visitado. Jonathan Culler ${ }^{6}$ afirmó que los lugares, los objetos, los gestos, no son parte de lo real, sino que están imbuidos por lo ideal. Este hecho produce una desilusión en el turista, desilusión que es parte integral de su experiencia como turista. Así, las ideas abstractas sobre un lugar están imbuidas por lo ideal, y esas ideas condenan al viajero a una desilusión y una melancolía ya que siempre estarán en ruta de colisión con al menos parte de la experiencia real. El viajero busca lo real, pero solo encuentra simulacros y copias, aunque según Dean MacCannell ${ }^{7}$ las cosas solo se conviertan en auténticas después de que alguien las haya copiado. Esta delicada relación entre realidad y copia es uno de los elementos constituyentes del turismo moderno, y posiblemente del turismo desde sus mismos inicios ${ }^{8}$.

Chamberlain, tal y como afirma, escribe Things Japanese para dar respuestas a visitantes en Japón. Es decir, establece una copia ideal de lo real (el Japón en el que vive), de forma que el ideal que crea transforma ese referente en "lo real". Lo hace además de forma muy aguda: por un lado, el formato que adopta, como comentamos, es el enciclopédico. Cada uno de los aspectos de Japón es una entrada en un diccionario, con un orden alfabético, un cuerpo explicativo y después de ello una bibliografía en muchos casos. Su obra se presenta así como una obra científica, lo que acentúa esa sensación de realidad. Por otro lado, usa del humor a lo largo del libro, lo que es un aparente contraste. Sin embargo, tanto a ese envoltorio realista y científico como a ese humor subyace un supuesto, una idea que da sentido a toda su obra: Japón es un mundo topsy turvy, es un mundo al revés que puede ser tratado científicamente o con humor. Y esta idea es la que determina al "otro", y la que define su "ideal". Japón es un mundo enfrentado, opuesto, reverso, cabeza abajo, un mundo al revés, unas antípodas culturales, en definitiva, del mundo occidental.

En su libro Metáforas de la vida cotidiana, Lakoff y Johnson ${ }^{9}$ estudian la metáfora en la lengua como instrumento cognitivo. La idea de su trabajo que nos interesa rescatar aquí es que las metáforas, sean del tipo que sean, sirven para establecer un marco de conocimiento que permite aprehender nuevas realidades. La aviación y el

5 Frow, John A. (1991): Tourism and the semiotics of nostalgia. October, (57), 123-151. http://hdl.handle. net/11343/34273 [Consulta: 22/09/2016]

6 Culler, Jonathan (1981): "Semiotics of Tourism", The American Journal of Semiotics, vol. 1, no. 1/2. http:// web.mit.edu/allanmc/www/culler1.pdf [Consulta: 23/09/2016]

Frow, John A. (1991): Tourism, op. cit.

8 La relación entre la copia y el original es uno de los mecanismos que puede salvar al turismo de su muerte por una masificación excesiva. La creación de reproducciones de lugares, edificios u objetos es una de los posibles vectores de desarrollo del turismo del siglo XXI.

9 Lakoff, George / Johnson, Mark / González Marín, Carmen (trad.) (2005): Metáforas de la vida cotidiana. Madrid: Cátedra. 
transporte aéreo, cuando comienzan, usan de la metáfora de la náutica y del mundo marino para establecer una realidad comprensible. Así, un avión llega a un aeropuerto, en el que los pasajeros embarcan en una aeronave. La metáfora nos sirve para asimilar lo nuevo y para establecer una red de significantes que nos permitan crear y dar sentido a nuevos significados. En el caso de la aviación, se asimila esta metafóricamente a la navegación, lo que permite un acercamiento conceptual a una nueva tecnología. Este hecho se refleja en el léxico de la lengua asociado a una nueva tecnología. Chamberlain, en este sentido, estableció una metáfora reveladora y a la vez simplificadora de Japón: se trataba de un mundo al revés. Por tanto, cualquier cosa de Japón tenía, por derecho propio, la naturaleza de ser contraria a otra cosa que estaba, de forma especular, en el mundo occidental. Siguiendo con esta aplicación del concepto de Lakoff \& Johnson, diríamos que Japón es un país nuevo en el conjunto de los países y necesita por tanto poder ser asimilado. Para facilitar esa asimilación Chamberlain usa la metáfora del mundo al revés.

\section{Cosas de España}

Chamberlain llamó a su libro Things Japanese, "Cosas de Japón”. En la breve introducción firmada en Minayoshita dice: "Y el título, que nos costó muchas meditaciones y que por fin tomamos de la frase española 'Cosas de España', ha tomado carta de naturaleza, llegando hasta proporcionar títulos a obras similares, escritas acerca de otros países en imitación de nuestro libro"10. Esta frase, sin embargo, no fue usada por primera vez por Chamberlain para un libro de esta naturaleza. Por una lado, existe Historia general de las cosas de la Nueva España, de Fray Bernardino Sahagún, escrito aproximadamente en 1550, una descripción de usos y costumbres de los americanos indígenas. De esta antigua referencia (dejando muchas otras por el camino), podemos pasar a la de 1845, año en el que Richard Ford publicó su famoso Handbook for travellers in Spain, y en 1846 Gatherings from Spain, conocido y traducido como Cosas de España ${ }^{11}$. Es interesante notar la similitud entre estas obras y las dos de Chamberlain que relacionamos con el turismo, no solo en el título, sino en los contenidos y las sendas cronologías relativas (Handbook for Travellers in Japan (1889) y Things Japanese (1890). De ahí que pensemos que un posible modelo para las obras de Chamberlain fuera, curiosamente, Richard Ford y sus trabajos sobre España.

Proponer esta influencia no nos parece descabellado. España, en el siglo XIX, se había convertido en "el otro" para los ingleses y franceses, un alter ego salvaje e idealizado, en el que el componente árabe se mezclaba con el latino y germano. Según esta visión idealizada, España era un país montañoso plagado por bandidos dispuestos a provocar la aventura más excitante, y mujeres ardientes prestas a llevar al intrépido viajero a la perdición. Como hemos apuntado, esta cosificación de los rasgos de un país no era nueva. Tras la obra de Fray Bernardino Sahagún, en la Espa-

10 Chamberlain, Basil Hall : Cosas de Japón... op. cit. p. 23.

11 Ford, Richard: Cosas de España (El país de lo imprevisto). Madrid: Jiménez Fraud Editor, 1922. (Traducción de Enrique de Mesa) Véase: https://archive.org/details/cosasdeespaael01ford [16-08-2016]. Es interesante constatar el subtítulo El país de lo imprevisto. Para los ingleses, España era el país de lo inesperado; Japón, el país del mundo al revés. 
ña de los siglos XVI y XVII abundan las crónicas de las cosas de la Nueva España, y las listas de curiosidades más o menos sorprendentes.

Si seguimos indagando la posible genealogía de ese título Things Japanese y su relación con la expresión "Cosas de España", encontramos también el libro de Sir Rutherford Alcock, The Capital of the Tycoon: a Narrative of a Three Years' Residence in Japan ${ }^{12}$. En él, cuando habla de las "Paradojas y anomalías" de la vida japonesa, menciona la expresión “Cosas d'Espana!", usándola en el sentido de cosas estrambóticas o particulares de un pueblo y con las que no queda más que transigir. Esto nos lleva a concluir que, quizá aunque Chamberlain no conociera la obra de Ford, ni su traducción al español, o tampoco las obras de los cronistas ibéricos, es seguro que conocía la obra de Alcock, puesto que la cita en su propia obra. Y es muy probable que Alcock conociera la obra de Ford.

El título es por tanto importante ya que, al fijar Japón en la rareza y la peculiaridad, anticipa lo que será una de las tesis principales del libro que hemos mencionado antes: que Japón se trata de un mundo al revés, un espacio topsy turvy en el que el viajero debe estar continuamente dispuesto a sorprenderse con lo raro, lo ajeno, lo contrario. Ahora bien, si el título hemos visto que no es propio de Chamberlain, sino que se inscribe en una tradición relacionada con descripciones de países con características que se clasifican como raras o extrañas, ajenas, ¿de dónde viene la idea de esta cualidad topsy turvy (una palabra, por otro lado fonosimbólica, con connotaciones orientales)? ¿Es creación suya o tiene una raigambre más antigua?

\section{El mundo al revés y sus raíces}

En la entrada del libro titulada de esa forma en el original Topsy Turvy (El mundo al revés en la traducción española), Chamberlain afirma: "Se dice a menudo que los japoneses hacen muchas cosas al revés de lo que los europeos piensan que es natural y adecuado. De igual manera, nuestra forma de hacer las cosas les resulta incomprensible a los japoneses." ${ }^{13}$ Esta cita condensa dos ideas: a. el mundo japonés y el europeo/occidental son dos mundos opuestos, uno al revés del otro; b. esa reversión de los mundos produce incomprensión recíproca.

Desde un punto de vista literario, en Inglaterra existen dos antecedentes relacionados con la reversibilidad de los mundos y su incomprensión, y los dos tienen que ver con el viaje: el primero, es Los viajes de Gulliver, de comienzos del siglo XVIII, libro construido sobre contrastes y absolutos (grande-pequeño, bueno-malo, etc.). El segundo, es Alicia en el país de las maravillas, publicada en 1865, en el que la idea del espejo y el mundo especular y reverso aparece como explicación del propio mundo. No cabe duda de que estos dos libros estaban muy influidos por la literatura de viajes: el primero, es una sátira y un uso alegórico de este tipo de libros, y el segundo usa muchos recursos del género para crear un viaje alrededor de la mente. Esta tradición anglosajona moderna, contrasta en cambio con la tradición hispana, en la que los libros de viajes fueron durante mucho tiempo crónicas: las crónicas de

12 Alcock, Rutherford (1863): The Capital of the Tycoon: a Narrative of a Three Years'Residence in Japan. New York: The Bradley Company, Publishers. Véase: https:/archive.org/stream/capitaltycoonan02alcogoog\#page/ n123/mode/2up/search/Cosas [Consulta: 29/08/2016] La URL anterior dirige directamente a la expresión Cosas d'Espana!

13 Chamberlain, Basil Hall: Cosas de Japón... op. cit., p. 344 
indias, relatos oficiales u oficializados de un carácter más descriptivo y científico, pero con un fondo providencialista justificativo de la conquista. Fuera de esta tradición, encontramos sin embargo los textos de jesuitas y religiosos sobre Japón. Se trata de textos escritos con objetivos muy concretos, fuera de la divulgación general, para uso de la propia orden. Son, en su esencia, obras de inteligencia en el sentido moderno, de recogida de información para ser usada por un grupo o estado con fines estratégicos.

Es bien sabido que los religiosos católicos, y sobre todos los jesuitas, tuvieron una gran influencia en Asia, con momentos de relativo esplendor en Japón. Sin embargo, también es sabida la forma en la que fueron expulsados finalmente de la isla en el siglo XVI, tras sucesos luctuosos. Pero en su esfuerzo adaptativo, crearon algunos de los textos más interesantes que se han escrito sobre la cultura japonesa, por su originalidad y por la ausencia de otras fuentes descriptivas. Entre ellos hay tres autores en los que encontramos referencias a Japón como un mundo al revés: Alessandro Valignano, Luis Frois y João Rodrigues. A continuación, nos referiremos a los dos primeros.

Valignano visitó Japón de 1579 a 1582 . En el año 1581 escribió El Ceremonial $^{14}$, obra escrita en portugués que tiene una traducción inédita al castellano ${ }^{15}$. La obra de Valignano es un defensa de la asimilación de los cristianos a los usos japoneses. Con ella, se convierte en un valido de las costumbres japonesas (catangues), que conoce bien y valora. Valignano fue precedido en esta idea por el valenciano Cosme de Torres y por el italiano Organtino ${ }^{16}$, pero sin duda él la desarrolló más. Desde el principio, Valignano fue consciente de la oposición entre el mundo japonés y el occidental: "E na verdade, como sejão seus costumes e modo de proceder de todo tão contrario os nosso, não hé maravilha se cahião em semelhantes opiniões." ${ }^{17}$ Sin embargo, esta oposición no implicaba, como en el caso de otro jesuita, Francisco Cabral, una valoración negativa sino que bien al contrario presuponía una valoración positiva de ese mundo opuesto.

Esa valoración positiva de Valignano de las cosas japonesas es constante en sus escritos. Por un lado, es notable su asimilación de términos japoneses, lo que indica su alto grado de aculturación. Esta es una lista no completa de términos que aparecen en El Ceremonial: cha-no-yu, zashiki, mochi, vino con sakana, shiru (caldo de Japón con alguna cosa de comer dentro), sai (guiso de pescado, carne y hierbas), sakazuki (cuenco de sake), inaka (aldea), ninsoku (porteador), itazura mono (vagabundo), kimono, machi-jin (urbanita), niwa (jardín), tatami, annai-sha (guía), hacer rei (hacer cortesía), mokurei (inclinación de cabeza), ken (1.8 m), tabi (calzado), ashinaka (sandalia), hyakusho (campesino), yakata (mansión), manju (tipo de empanadilla), tsukemono (encurtido), hashi (palillo), tokkuri (botella de sake), taru (barril), nam-

14 Este título fue asignado por Álvarez Taladriz, sin que aparezca en el título original de la obra. Aquí, lo usaremos cuando nos refiramos a él, aunque en la bibliografía usaremos el más largo y fiel al original usado por Marino en la edición que usamos y que incluimos en la bibliografía.

15 Valignano, Alessandro / Marino, Giuseppe (trad.): Sobre las costumbres de Japón. Manual de adaptación. Inédito. Esta obra ha sido traducida por Marino del portugués al español. La obra, con un prólogo del traductor, está inédita aunque parece que tendrá una pronta publicación.

16 Ibidem.

17 Valignano, Alessandro / Wicki Josef (ed.) (1944): Historia del principio y progresso de la Compañia de Jesús en las Indias orientales (1542-1564). Roma: Instituto Historico, Borgo S. Spirito, pp. 356-357. 
ban (bárbaro del sur), shoogatsu (año nuevo), futomono (tela), mezurashimono (objeto curioso), katabira (kimono ligero), etc.

En vez de explicar estos términos japoneses con palabras portuguesas, El Ceremonial está escrito originalmente en esa lengua, Valignano usa el japonés, adaptado fonéticamente en ocasiones, lo que lleva al lector a una aculturación involuntaria. Por otro lado, esa misma no traducción del término refuerza la idea de mundo opuesto, en el sentido de que lo intraducible es más contrario.

Conviene notar también que El Ceremonial es sobre todo una obra procedimental, ya que se centra en formas de hacer las cosas. Sin embargo, en esa descripción de maneras y ritos, surge la cosificación, la enumeración y descripción de objetos que participan en esas costumbres. De esta forma, no solo las costumbres sino también los objetos adquieren una naturaleza contraria y diferenciada, aspecto que tendrá una enorme popularidad y una gran influencia en al arte en Occidente durante el siglo XIX de la mano del japonismo.

En cualquier caso, la metáfora de Japón como un mundo opuesto, un mundo al revés, sirve a Valignano de marco conceptual en el sentido de Lakoff \& Johnson para facilitar la comprensión de ese mundo a los que se enfrenten a él. Valignano es seguramente consciente de que un mundo opuesto es de más fácil asimilación que un mundo similar. En este sentido, la diferencia, e incluso la oposición, pasan a ser un mecanismo cognitivo más, al resultar una metáfora asimilativa.

Valignano desarrolló esta idea del mundo contrario en su Sumario de las Cosas de Japón ${ }^{18}$, pero es Luis Frois con su Tratado ${ }^{19}$ quien la lleva a su esplendor. Es imposible no leer el Tratado de Luis Frois sin relacionarlo con Things Japanese de Chamberlain. Parece también difícil leerlo sin tener la sensación de que Frois es un consumado escritor, un antropólogo sagaz, y un hombre de método intelectual. La cosificación de la cultura japonesa en su obra es notable, pero en ningún momento deja de lado las costumbres ni los modos sociales. Por un lado, su obra está escrita casi como una enumeración agrupada temáticamente, lo que la acerca mucho a un diccionario o a una enciclopedia. Frois es un enciclopedista avant la lèttre y avant Chamberlain. Para empezar, escribe en dísticos que expresan siempre una oposición:

a. Los europeos son, en general, altos y bien formados; los japoneses son, en general, menos altos y menos robustos, o

b. Los europeos consideran que los ojos grandes son bellos; los japoneses piensan que los grandes son horrendos, y consideran bellos los ojos estrechos en los extremos.

Esta oposición formal refuerza la oposición temática y de contenido. De un lado, están los europeos; de otro, los japoneses, siempre diferentes, siempre opuestos. Frois, si no el creador, es el real impulsor del topsy turvy trescientos años antes que Chamberlain. Sin otras referencias por el camino, su Tratado se levanta como una enciclopedia amena, a veces incluso mundana, siempre ilustradora, de las particu-

18 Valignano, Alessandro / Álvarez-Taladriz, José Luis (trad.) (1954): Sumario de las cosas de Japon, 1583. Adiciones del sumario de Japon, 1592. Monumenta Nipponica monographs; no. 9, Tokyo: Sophia University.

19 Fróis, Luís / De la Puente Ballesteros, Ricardo (ed.) (2003): Tratado sobre las contradicciones y diferencias de costumbres entre los europeos y japoneses (1585). Salamanca: Ediciones Universidad. 
laridades de la cultura nipona. Y siempre con este mensaje latente: "Japón es un mundo al revés, un mundo contrario".

Sería bueno poder trazar una línea que uniera Chamberlain y Luis Frois. Cualquier lector que tenga acceso a sus obras seguro que se siente inclinado a hacerlo. Y no será el primero. Claude Lévi-Strauss, en su breve introducción a la versión francesa del Tratado, afirma:

La symétrie qu'on reconnaît entre deux cultures les unit en las opposant. Elles apparaissent à la fois semblables et différentes, comme l'image symétrique de nous-mêmes, réfléchie par un miroir, qui nous reste irréductible bien que nous nous retrouvions dans chaque détail. [...] C'est aussi en faisant appel à la symétrie que Froís, sans le vouloir, car c'était encore trop tôt, et Chamberlain en le sachant, nous offrirent un moyen de mieux comprendre la profonde raison pour laquelle, vers le milieu du XIXe siècle, l'Occident acquit le sentiment de se redécouvrir dans les formes de sensibilités esthétique et poétique que lui proposait le Japon." ${ }^{20}$

La idea de Lévi-Strauss es doble: por un lado, Frois y Chamberlain están los dos relacionados; por otro, los dos ofrecen una visión especular de Occidente en la que el propio Occidente se busca y se descubre. Japón es el otro y es el revés de uno mismo. Sin embargo, establecer una relación directa de influencia entre Frois y Chamberlain parece imposible. La obra de Frois no fue publicada por él ni por la Compañía de Jesús, y no fue hasta casi los años 50 del siglo XX que Schütte descubrió en la biblioteca de la Real Academia de la Historia en Madrid el manuscrito de Frois, lo que hace virtualmente imposible que Chamberlain la leyera. No hay razón, por más que sean primos hermanos por forma y por contenido, para pensar que Chamberlain haya recibido influencia directa en su Things Japanese de la obra del portugués. Sin embargo, Gill aporta en su libro Topsy-turvy 1585: A Translation and Explication of Luis Frois S.J. 's Tratado ${ }^{2 I}$ la línea de autores que, desde Valigano y Frois, han usado esta idea de oposición y mundo al revés. Su propuesta es la siguiente: Valignano (Sumario, 1583) y Frois (Tratado, 1585) serían los creadores del primer desarrollo de esta idea; los siguientes autores serían difusores de ella: Gian Pietro Maffei con la Historia de las Indias, América, India, Japón, y las misiones jesuiticas (1590), Van Linschoten con The voyage of John Huyghen van Linschoten to the East Indies (1598), Francesco Carletti con Raggionamenti del mio viaggio intorno al mondo (1597), Arnoldus Montanus con su Atlas Japannensis (1670), Monsieur L'Abbé de T. con la Historia de la iglesia de Japón, libro basado en Valignano, Rodrigues y Maffei; luego, entre los autores anglosajones, Sir Rutherford Alcock con Capital of the Tycoon (1863), Percival Lowell en The Soul of the Far East (1888), hasta llegar a Chamberlain.

A través de estos autores, es posible establecer una línea de influencia conceptual, ya que todos usan la idea del mundo opuesto y contrario, entre Japón y Occidente. En ese sentido, aunque Chamberlain no hubiera tomado directamente ideas de Frois,

20 Frois, Luis / LÉVI-STrauss, Claude (prefacio) (1998): Européens \& Japonais : traité sur les contradictions \& différences de mours. Paris: Chandeigne, p.9.

${ }_{21}$ Gill, Robin G. (2004): Topsy-turvy 1585: A Translation and Explication of Luis Frois S.J.'s Tratado. Florida: Paraverse Press. 
su obra se incluye en un mismo discurso de Japón como un cuerpo complejo clasificable siempre por la reversión de su interpretación del mundo. Y no es descabellado pensar en una influencia indirecta.

\section{Conclusiones}

En nuestro trabajo hemos visto que Chamberlain escribe una guía cultural destinada a viajeros, que complemente su guía de viaje. Aunque afirma que su intención es dar respuestas a las preguntas que le hacen viajeros en las islas, su alcance va más allá y constituye una enciclopedia sobre el Japón Meiji y el Japón más tradicional. Eso no impide que tenga una naturaleza muy moderna, al mezclar documentación con humor y experiencia personal en una suerte de Lonely Planet del siglo XIX. Su vigencia fue tremenda, y Donald Keene nos comentaba que estudió el libro en la Universidad de Coliumbia en los años 40 del siglo pasado.

Things Japanese se tradujo de forma muy temprana al español, en la segunda década del siglo XX, por Gonzalo Jiménez de la Espada ${ }^{22}$, profesor de español en la Tōkyō Gaikokugo Gakkō (Escuela de Lenguas Extranjeras de Tokio) de 1906 a 1916. La traducción se conservó parcialmente y no se ha recuperado hasta el año 2014. De haberse publicado en la década de los veinte o los treinta, es seguro que el conocimiento de Japón en España habría sido muy diferente.

Things Japanese, el libro de Chamberlain, muestra dos aspectos peculiares. El primero, es su título, del que hemos buscado su relación con obras españolas, la tradición que se inicia en las Crónicas de Indias, o sobre España, como son los trabajos de Richard Ford. El otro aspecto interesante, es la idea de que Japón es un mundo al revés, un mundo topsy turvy. Hemos defendido que dicho concepto es una metáfora cognitiva en el sentido de Lakoff \& Johnson. Además, hemos estudiado la relación de dicho concepto con obras de religiosos jesuitas que vivieron en Japón, en concreto Valignano y Frois. De ellos sus obras, hemos dado especial importancia a la de Frois, y aunque sabemos que la relación directa entre uno y otro es imposible de establecer, hemos buscado la posible relación indirecta. Creemos que es plausible defender que el origen de Japón como mundo al revés que desarrolla Chamberlain tiene su origen en la visión de los dos jesuitas. En este sentido, Japón fue un mundo al revés para Occidente, muy poco después de los primeros contactos entre los ambos mundos.

22 Para más información sobre Gonzalo Jiménez de la Espada véanse: (2016): PAZÓ ESPINOSA, José y ALMAZÁN TomÁs, David (2016): “Gonzalo Jiménez de la Espada: A Meiji-Era Spanish Professor and Translator in Japan”. En Penas IbáÑez, Beatriz / Manabe, Akiko. (eds.) Anglo-American Literature, Art and Film in (Late) Modernism, Berna/Berlin/New York: Peter Lang, pp. 65-89.

Pazó Espinosa, José (2016): “Gonzalo Jiménez de la Espada y su labor como traductor y japonólogo en el primer tercio del siglo XX”. En: Gómez Aragón, A. (ed.): Japón y Occidente. Col. Textos Universitarios, 37. Sevilla: Aconcagua Libros, pp. 407-417. 